\title{
Una estética del ícono en el pensamiento de San Agustín
}

\section{LA EXPERIENCIA DEL LECTOR}

Cada lector, a partir de su experiencia insustituible, no termina de agradecer el clima de serena intimidad y de exigente realismo que instala Agustín desde sus primeras palabras. Este clima no corresponde solo a un dispositivo psicológico, cualquiera sea su importancia para la cognición o para el juicio de la razón práctica en la vida ética (1). Más importante aún, el clima mencionado resulta favorable para que el lector posible recorra un camino junto con Agustín. Este camino es, ante todo, el de la caridad, experimentado como la búsqueda incesante del Rostro del Señor Dios (2). Un rasgo universal y, entonces, también contemporáneo se destaca en las palabras del Hiponense: el camino por recorrer es el de la investigación y este debe contar con la experiencia de la duda y el error, no ciertamente como algo que se elige, sino, más bien, como algo que, a pesar de todos nuestros mejores esfuerzos, no siempre podremos evitar.

En todo caso, Agustín propone -más allá de todas las dificultades posiblesuna actitud totalmente positiva que es la de una verdadera sinergia entre la inteligencia del lector y la del Autor en la búsqueda en común de la verdad. Agustín recupera la experiencia dialógica de la investigación de la verdad con aquella ten-

(1) En este trabajo queremos reconocer nuestra deuda de admiración y gratitud a la persona de la Profesora Isabelle Bochet y a su libro Saint Augustin et le désir de Dieu, Paris Études Augustiniennes, 1982. Así también deseamos expresar nuestro reconocimiento por su valiosa referencia del libro de Carol Harrison, Beauty and Revelation in the Thought of Saint Augustine, Oxford, Clarendon Press,1992. Ambas scholars nos han permitido conectar interiormente el tema del deseo de Dios en San Agustín con el tema del icono que venimos estudiando hace años.

Ver Martin Rhonheimer, La prospettiva della morale. Fondamenti dell'etica filosofica, Roma, Armando Editores, 1994, Capitolo quarto: Le virtù morali. c. La dimensione antropologica e affetivo-cognitiva della virtù morale, pp. 169-172, ver nota 2 y el importante comentario referido a la participación de las pulsiones de los sentidos en la razón, S.Tomás, S.Th. I-II, q. 58 a. 2, y la idea agustiniana de las virtudes como ordo amoris, De Civ. Dei, XV, 22.

(2) Ver De Trin. I, 3, 5: "Que mi lector, si comulga plenamente en mi certeza camine conmigo; si comparte mis dudas, que busque conmigo; si se reconoce en el error, que vuelva a mí; si me sorprende en él, que me aparte de este. Así avanzaremos juntos en el camino de la Caridad, hacia Aquel de Quien está escrito: 'Buscad sin cesar mi Rostro'. He aquí el voto piadoso y firme que yo querría hacer delante del Señor con todos mis lectores, a través de todas mis obras, mis escritos”. Ver además, Isabelle Bochet, Saint Augustin et le désir de Dieu, ed. cit., 1982, p. 1, n.1. 
sión antropológica y divina que mostró magníficamente, en su momento, Platón. En el caso de Agustín, se trata de un Autor que no sabe aquello que va a decir antes de escribir sino que, por el contrario, solo logra saberlo cuando escribe dialógicamente. En efecto, el doctor de Hipona no escribe dictaminando o demostrando in recta via, ya que en cualquiera de los dos casos sería preciso disponer por adelantado de aquello que se va a decir, y esto con toda claridad y precisión. Si se pudiera hablar así, quisiéramos señalar que Agustín escribe [y piensa] según un principio musical que tiene en cuenta no solo la $v o z$ del otro y su correspondiente realidad personal sino, también, toda la riqueza de su contenido significativo, haciendo posible así una cooperación, que es una armonía contrastante, como aquella tarea humana en la que se realiza la búsqueda de la verdad en el logos, es decir: en el dialogos. La escritura agustiniana asume -en principio- la realidad de lo incierto y la correspondiente necesidad de reducirlo, en lo posible, por la vía humilde del asedio, a la concentración, que crece en la medida en que se circunscribe un tema o un problema en el pensar, con la plena convicción de que el movimiento iniciado en el fervor especulativo jamás agotará su objeto en una explicitación exhaustiva. Antes bien, habrá que, una y otra vez, reiterar el pensar en su asunto hasta alcanzar, respecto de este último, familiaridad y reverencia.

Ahora bien, si como conviene al interés preciso de nuestro tema entendemos que la experiencia del acto de lectura se corresponde con la experiencia del acto del caminar a través de un cierto camino, habrá que admitir que, en esta hipótesis, quien camina lo hace movido por algo. Este algo que conmueve al Autor que es Agustín y que espera compartir con sus lectores posibles es, ciertamente, el deseo de Dios (3). Este deseo, absolutamente incomparable con cualquier otro que el hombre pudiera experimentar, hace que los límites racionales de la investigación sean desbordados. En efecto, no se trata simplemente de conocer algo sino, ante todo, de amar a Alguien. Pero este desborde del que se habla aquí no implica una oposición entre la razón y la fe, sino la unión e integración de una con la otra. Es manifiesto, además, que a partir de la realidad viviente del deseo de Dios se abren dos perspectivas: la de la relación del hombre con Dios y la de la relación de Dios con el hombre. Entre dichas relaciones hay una subordinación que obedece a la constante y perfecta iniciativa de Dios en todo.

\section{UNA PEDAGOGÍA ELEMENTAL DEL DESEO}

La primera lección de la pedagogía del deseo en Agustín es que si bien el hombre es sujeto de un deseo de Dios, Dios no es un objeto entre otros objetos, ya que todo objeto de deseo por parte del hombre es necesariamente relativo. Solo Dios es absoluto, por tanto solo Dios basta, ya que solo Dios puede y debe referirse únicamente a sí mismo y, de este modo justifica perfectamente que se lo busque solamente a Él como un fin o bien absoluto en sí mismo. El deseo de Dios introduce una necesaria y legítima discontinuidad en la experiencia de los múltiples deseos del

(3) Explicar esto a través de la Obra y el pensamiento de Agustín es el propósito del bello libro de Isabelle Bochet, Saint Augustin et le désir de Dieu, op.cit. passim. 
hombre, porque este deseo de Dios no puede añadirse a aquellos sobre el mismo plano. Más aún, mientras los deseos posibles en el hombre tienden no solo hacia la multiplicidad sino, también, hacia la dispersión, Dios, en virtud del carácter absolutamente único de su realidad, acoge y recapitula todos los deseos unificándolos en orden a su ser único y último en cuanto fin y bien. Todo ocurre como si en la experiencia de la multitud de los deseos que se corresponde con la multiplicidad de sus objetos, el hombre, en algún momento, experimentara un vacío repetido que lo vacía. El hombre experimenta así la desproporción entre su capacidad connatural para desear y la finitud inevitable de todos los objetos, aun aquellos que él mismo reconoce como nobles y superiores. La curva metafísica del deseo hace que este -bajo estas condiciones- revierta sobre la voluntad y descubra la experiencia del desierto. En suma: el hombre descubre en su propia realidad una orientación ontológica hacia Dios. Está claro que en razón del mal uso de su libertad, todo hombre puede negarse deliberadamente a seguir dicha orientación, lo cual equivale en el acto de existir a sustraerse al orden que lo constituye en su ser y movimiento propios. Esa orientación radicada en su ser es la marca y el dinamismo de su condición de creatura.

Ahora bien, admitido esto, aparece la cuestión primordial del deseo de Dios, a saber: ¿cómo es posible que una creatura finita pueda desear a Dios infinito?, ¿cuál realidad podría mediar en el abismo ontológico que separa a la creatura del Creador y hacer posible este deseo? Se responde solo Dios, quien está en el comienzo y el fin de este deseo de Dios en el hombre. Esta idea comparece en el De Trinitate, XV, 2, 2: "Aquel a quien se busca para hallarlo" es el mismo que "se halla para seguir buscándolo". La lógica del deseo de Dios exige que Dios sea inmanente y trascendente a la vez. Dios debe hacerse presente al hombre -de alguna manera- para que este lo desee y lo conozca en cuanto esto es posible para el hombre, ya que, sin duda, Dios es absolutamente trascendente al hombre y es inconmensurable respecto de todos los objetos que desea o conoce en su experiencia. Porque Dios es absolutamente trascendente a todo, puede hacerse inmanente a la experiencia del hombre, y, así, el hombre puede sostener un deseo genuino y legítimo de Dios. En efecto, Dios no solo se hace presente en la intimidad más sustantiva del corazón humano sino que, además, desde allí llama al hombre. En este sentido, la experiencia del deseo de Dios muestra cómo y por qué es posible una metafísica de la vocación humana. Dios no solo crea al hombre sino que desde su ser creado lo llama. Aquí se da la realidad de un diálogo intratrinitario que llama al hombre desde su ser y, por otra parte, la realidad de la persona del hombre que en el ejercicio pleno de su libertad responde. Aquí la ontología está presidida por el diálogo personal entre dos libertades: la libertad infinita y convocante de Dios y la libertad creada y vocacional del hombre. Aquí, ser es vocación.

La segunda lección de esta pedagogía elemental del deseo consiste en advertir que el hombre puede buscar a Dios porque Dios -primero- en Cristo, lo busca sin cesar, lo llama sin desfallecer, y hace todo esto a través de los obscuros meandros de la multitud de los deseos del hombre. En este punto no cabe una consideración abstracta del deseo humano sino, ante todo, un agudo y sincero realismo para advertir que la multitud de los deseos puede reducirse a un único, absoluto y total deseo que se ordena a Aquel que en su ser y obrar es Todo. La tercera lección en cierto modo se halla implicada en la segunda y apunta a la curva del deseo humano en su posibilidad de enfermar pero, también, de sanarse. La enfermedad del deseo no estaría tanto en la 
dispersión en una multitud de objetos deseables, cuanto en una búsqueda siempre sutil, frecuentemente intensa, de sí mismo, en la que el sujeto del deseo se toma a él mismo como su único objeto. La enfermedad es aquí la substitución de lo único y la consecuente clausura sobre lo propio, el yo referido totalmente a sí mismo.

Con enorme penetración de las realidades que constituyen la psicología espiritual, Agustín advierte que la verdadera cuestión no consiste en saber si puede -o no- prescindir de este o aquel placer sino, más bien, con cuál grado de tristeza lo haría en cada caso. Aquí la variedad multiforme de los deseos ha hecho del hombre un esclavo que se complace con su esclavitud. Esta experiencia promueve, en quien la vive, el sentimiento de la lejanía de Dios, un vivir y estar lejos. Este vivir lejos puede traducirse, también, como un errar que es grave no solo por la distancia que introduce respecto de Aquel que es fin y reposo último sino, además, por la índole del desorden que afecta al deseo. Aparece, así, la experiencia del olvido de Dios.

Debería llamar nuestra atención el hecho de que para hablar de esta realidad profundamente espiritual, Agustín recurra a experiencias que, en general, proceden del orden del cuerpo, dando testimonio, entonces, de la profunda unidad espiritual-corporal con la que piensa al hombre. El Hiponense menciona la saciedad y el sopor. En efecto aquel que declara estar saciado rechazará aun los manjares más exquisitos (En In Ps. CXXXI, 24). La experiencia de la posesión en abundancia de bienes materiales o aun de bienes espirituales puede conducir al hombre necio a cerrar su corazón a la urgencia del deseo de Dios, en la falsa convicción de que ya no necesita nada. Su avidez lo ha convertido en un satisfecho y, en este caso, en alguien que ya no espera nada de Dios, sino que confía y espera solo recibir bienes de la tierra y de la historia en favor del vigor de sus fuerzas y de la inteligencia de sus iniciativas.

En cuanto al sopor, este síntoma aparece como más grave aún. En realidad se trata de una anestesia provocada por la inmersión completa en los placeres del mundo. De este modo el hombre se hunde en un sopor cada vez más pesado y artificial que lo hace más y más insensible para el mundo del espíritu y para Dios. Se experimenta un estado de inercia y el alma se hace pesada. En suma: el hombre ya no vela ni vigila. Ya no puede levantarse e ir a Dios (Confes. VIII, 5, 12): su existencia se ha curvado y cerrado sobre sí misma.

\section{LA CUESTIÓN DE LA IMAGEN COMO ÍCONO}

La cuestión de la imagen debe ser situada en el orden del acto humano de ver. Cuando la imagen alcanza la significación específica de ícono, aparecen dos modos posibles de ver, que el poeta Georges Herbert propone en su poema Elixir.

"a man that looks on glass

on it may stay his eye;

or if he pleaseth, through it pass,

And then heaven espy" (4). "al mirar un espejo

el hombre puede en él detener sus ojos; o bien, si es su deseo, mirar más allá y así atisbar el cielo" (4).

(4) Debo el conocimiento de este bello y significativo texto al precioso libro de Carol Harrison, Beauty and Revelation in the Thought of Saint Augustine, ed. cit. En este punto seguimos esta muy fina investigación. 
Hay, entonces, un mirar humano que se dirige a las cosas y se detiene en ellas; y otro que mira a través de las cosas, que es propio de los que buscan, con su mirada, la belleza, la verdad, el ser y, en el caso de Agustín, Dios. Este segundo modo de mirar es, si se pudiera hablar así, itinerante. Comporta una capacidad para atravesar la realidad sin devaluarla jamás en su estatuto y establece, así, un saber que es, él mismo, un camino. Un camino a través de las cosas que se miran y se ven. El texto del poeta Georges Herbert, tiene un eco en las palabras de San Pablo en I Cor., 13: "ahora vemos en un espejo, en enigma, entonces veremos cara a cara" (5).

Por otra parte, hay que distinguir entre mirar a un espejo y mirar a través de un espejo, que en tiempos antiguos era fatalmente oscuro. En efecto, los espejos antiguos -como se recuerda- eran de metal pulido y, en general, entregaban imágenes más o menos obscuras que, en cada caso, reclamaban un peculiar esfuerzo de discernimiento. Había que mirar y ver a través de un espejo -per speculum- figuras y formas inteligibles. Este mirar y ver se hallaban, siempre, mediatizados. El Apóstol señala lo imperfecto de esta situación y la compara con la que caracteriza al hombre que vive en el tiempo de la historia y, desde la experiencia de la fe, mira y trata de ver y juzgar todo. Este modo de mirar y ver debe ser comparado, además, con dos momentos diversos: uno, el de la experiencia preternatural del hombre, en la que este era connaturalmente contemplativo de la realidad divina de Dios; otro, escatológico, en el que se promete al hombre contemplar a Dios facie ad faciem y donde ver sea, efectivamente, existir.

En otro sentido, la cuestión de la imagen como icono debe situarse en la experiencia de la lengua en la que habla, piensa y escribe Agustín. Esta lengua fue la latina y el santo doctor aportó a ella su experiencia intelectual y estética de retórico. Se trata de una inteligencia y una sensibilidad frente a la realidad de las palabras que permite caracterizar el pensamiento de Agustín, con razón, como acústico. Este hecho nos interesa y nos ayuda a fijar la pregunta que guía nuestra aproximación y que concierne a la totalidad del pensamiento del Maestro de Hipona: ¿es posible concebir su vasta y rica meditación filosófico-teológica fuera de su experiencia profunda de la belleza? Un primer nivel de la posible respuesta pasa a través de la lengua que utilizó Agustín. Allí species, forma -figura, forma- dicen relación a speciosus, formosus, hermoso. En el latín agustiniano se podían, mencionar conjuntamente la realidad inmediata y visible de las cosas y su realidad arquetípica y última; se podían nombrar las figuras actuales y las realidades últimas correspondientes, en cuanto que la belleza era la característica común de ambas. Esto mismo, después, aparece arrastrado a la disyunción y a la separación definitiva en otras lenguas y modos de pensar. Agustín todavía puede pensar y

Sobre una consideración filosófica del tema de la imagen como icono Cf. H.J. Padrón, Elementos para una filosofía del icono. A.S. Said y J.L. Marion. Una confrontación in Philosophia (1994), pp. 115-140. Quiero agradecer, además, las valiosas sugerencias e indicaciones que me hiciera, oportunamente, sobre el tema de la imagen como icono, la Profesora Isabelle Bochet del Centre Madelaine Daniélou de París.

(5) El ver en S. Pablo está propuesto en el orden del conocer, Cf. I Cor. 13, 12: "Ahora conozco de un modo parcial, pero entonces conoceré como soy conocido". Cf. ad. II Cor., 5, 7: "pues ahora conocemos en la fe y no en la visión". Este conocimiento asume, ciertamente, la desproporción infinita que hay entre el hombre y Dios. 
decir, solidariamente, lo inmediatamente íntimo y lo último de la forma y el ser a través de la experiencia de la belleza. Allí, precisamente, es donde cuenta la realidad y la función de la imagen como ícono.

Es cierto que para la óptica cristiana del pensamiento de Agustín, el hombre, a causa de la caída original, ha perdido la intuición de la Belleza Divina, pero no es menos cierto que ahora, a favor de un esfuerzo noble de su mirar a través del velo de la temporalidad y la corporalidad de las cosas creadas -Iluminación mediante- el hombre puede reiniciar el camino, siempre arduo, de una contemplación genuina y legítima de la belleza que, cuando es justa, conlleva la tarea excelente y profunda de su reforma -reformare- en razón de su deformación -deformatio- y su consecuente afeamiento en su ser. En todo caso, Agustín enseña que la iniciativa de este proceso -exigente- pertenece exclusivamente a Dios y a su divina Belleza que, en su dignación, inspira al hombre fe, esperanza y, sobre todo, amor de caridad, a fin de que su mirada pueda finalmente - previa purificación- ver sin ocaso. Entre tanto, la filosofía tiene el mayor interés en indagar la realidad y el dinamismo peculiar de la imagen como ícono, ya que a través suyo se incoa en el espacio y el tiempo la visión que un día será plena.

El desarrollo posterior depende de unos pocos puntos que deben quedar claros. (1) Creemos que la cuestión de la imagen como ícono debe ser propuesta en el contexto teórico de la meditación agustiniana sobre la belleza. Esta meditación atraviesa la totalidad de su obra con diferentes contextos y modulaciones. Atender a esta diferencia de contextos y de matices hace posible el camino de una interpretación que intenta una alternativa a las dificultades y aporías de prestigiosos scholars. (2) Recordamos, ante todo para nuestro uso personal, que hay un solo Agustín, más allá de las notorias diferencias -y dificultades- entre los escritos tempranos y aquellos otros correspondientes a la madurez y a la última etapa del santo doctor. (3) La consideración de la imagen como ícono puede servir como elemento para la reflexión sobre los dos grupos de textos: tempranos y de madurez, incluidos los finales. (4) La cuestión de la imagen como ícono se inserta en la realidad de una estética de Agustín que es preciso discernir e interpretar adecuadamente en el seno de un debate serio de los estudios actuales.

\section{LA CUESTIÓN DEL HORIZONTE TEÓRICO EN LA ESTÉTICA DE AGUSTÍN}

\section{La pertinencia de la realidad del ícono}

La aproximación a la estética de Agustín como el horizonte teórico donde se plantea la cuestión de la belleza ha sido realizada por tres estudiosos a través de obras de enorme interés, con méritos diversos y útiles para nuestro tema: la imagen como ícono en el pensamiento agustiniano. Se trata de K. Svoboda (6), R.J. O’Connell (7) y C. Harrison (8).

(6) Cf. K. Svoboda, L'esthétique de saint Augustin et ses sources, Brno, 1933.

(7) Cf. R.J. O'Connell, Art and the Christian Intelligence in Saint Augustine, Oxford, 1978

(8) Cf. C. Harrison, Beauty and Revelation in the Thought of Saint Augustine, ed. cit. 
El tema de la belleza es prioritario para la investigación que llevó a cabo Svoboda. El Autor realizó el análisis de cada trabajo en su orden cronológico, tanto en lo que concierne a los trabajos tempranos, cuanto en lo que se refiere a los trabajos posteriores en la curva histórico-especulativa del doctor de Hipona. En todos los casos la indagación es meticulosa, y el cuidado por señalar las fuentes del pensamiento agustiniano es constante y presta un inestimable servicio para los estudios posteriores.

La tesis de Svoboda declara que la estética de Agustín es, ante todo, racional, espiritual, matemática, con raíces pitagórico-platónicas. Señala estos rasgos para los escritos tempranos donde, precisamente, ha buscado la concepción estética de Agustín. Para el corpus de los textos posteriores utiliza el mismo método cronológico, destaca todas las referencias a la cuestión de la belleza usando -hélas!- como paradigma de su interpretación las palabras que aparecen en los escritos tempranos. Añade la indicación precisa y rica de las fuentes. Hay que señalar que el trabajo de Svoboda es sobre todo descriptivo, no hay en él una reflexión consistente sobre los datos que encuentra y, tampoco, se halla en su libro una conclusión sobre la ingente masa de materiales examinados. A este hecho se agrega que el método utilizado introduce una perturbación seria para la eventual interpretación de la estética de Agustín. En efecto, Svoboda utiliza las afirmaciones de los trabajos tempranos de Agustín de manera aislada y, por otra parte, les asigna un valor paradigmático para la consideración del corpus posterior. Finalmente, en términos generales, sostiene que la estética de este período es cada vez más espiritual, es decir: esencialmente racionalista $\mathrm{y}$, en su conjunto, negativa respecto a la realidad de las cosas creadas, las cosas corpóreas, inscritas en el tiempo y el espacio, las cosas inevitablemente caducas incluidas las obras de arte que hace el hombre. Svoboda declara que esto es así -estética espiritual- en la medida en que su pensamiento estético se ve cada vez más influido por el cristianismo. Varias observaciones se imponen aquí. Por una parte, las afirmaciones estéticas de Agustín no se pueden considerar aisladas sino, precisamente, en su respectivo contexto; por otra parte, las afirmaciones estéticas correspondientes a los trabajos tempranos poseen un importante nivel teórico que es preciso reconocer; sin embargo, este hecho no autoriza a tomarlas como un paradigma de otras afirmaciones que corresponden al corpus textual posterior del doctor de Hipona. Por último, la consideración atenta de los contextos de las distintas afirmaciones permite comprender y justificar las variaciones en el acento puesto en un caso y en otro, ya que se trata de momentos histórica y especulativamente diversos (9). De todos modos, lo inaceptable de la tesis de Svoboda consiste en sostener que la devaluación de la realidad corpórea, sensible, temporal y mudable de los cuerpos en la estética agustiniana se debe a la influencia, en el Autor, de la experiencia del Misterio cristiano. La verdad es exactamente lo contrario. La experiencia del Misterio cristiano y su reflexión filosófico-teológica exigen una consideración seria, atenta y profunda de todas las realidades creadas, particularmente las realidades corpóreas. Esta atención y consideración francamente positivas proceden de la exigencia de la Creación, de la Encarnación, de la Providencia divina en cuanto gobierno en la 
historia concreta de los hombres y de las cosas de la mens divina, para mencionar solo algunas referencias que una estética cristiana no puede ignorar sino, por lo contrario, integrar armoniosamente. Esto explica que aun en el período inicial de los escritos tempranos, Agustín sea mucho más positivo que lo que sostiene Svoboda respecto de la belleza del reino temporal. Basta recordar el contexto y las afirmaciones que se pueden hallar en el Contra Académicos.

No se trata de negar el hecho de que la estética de Agustín revele influencias filosóficas cuyas fuentes se puedan identificar con bastante precisión; se trata de saber en qué medida la estética en cuestión se halla influida por la experiencia cristiana y qué consecuencias contrarias a la tesis de Svoboda se pueden extraer de este otro hecho. Por otro lado, Svoboda propone que la cuestión de la belleza tuvo en Agustín un trámite filosófico con afirmaciones teóricas que -en su interpretación- destacan el carácter abstracto de su pensamiento estético y, en definitiva, la poca importancia que la cuestión de la belleza habría tenido para el desarrollo posterior del pensamiento filosófico y teológico de Agustín (10). Por nuestra parte, negamos que este sea el caso en la estética de Agustín.

Veamos, ahora, el aporte que efectúa R.J. O’Connell a la índole de la estética de Agustín como el lugar donde se plantea naturalmente la cuestión de la belleza y, con ella, la de la imagen como ícono, que es, precisamente, el tema de nuestra indagación.

O’Connell comienza por preguntarse -con razón- si la tesis de Svoboda puede dar cuenta de la estética agustiniana, afirmando que, ante todo, dicha estética es esencialmente racional, es decir: matemática y, en suma, negativa para la apreciación de todo lo que constituye, con derecho pleno, el reino de lo temporal, lo corpóreo, lo caduco, que, sin embargo, se presenta como bello. Más aún, se pregunta por qué -en la práctica- algunos textos agustinianos manifiestan una dimensión imaginativa y creativa riquísima que, aparentemente, ciertas declaraciones teóricas de los escritos tempranos parecen excluir. Para intentar responder a estas preguntas, O'Connell recurre al lenguaje de Agustín en sus textos, particularmente al texto de las Confesiones. Allí da otro paso decisivo para su análisis, que resulta precioso para el interés de nuestro tema. En efecto, O'Connell estudia el lenguaje artístico de las Confesiones a través de las imágenes que emplea su Autor.

La tesis de O'Connell consiste en afirmar que la práctica textual de Agustín trasunta una teoría que excede los límites que reconoce Svoboda en los trabajos tempranos y que -como intentamos mostrar- reduce la teoría estética de Agustín a un racionalismo y un espiritualismo inaceptables. En suma: O'Connell muestra el interés de Agustín por la cuestión estética y lo hace en el registro de su lenguaje artístico. Esto le permite ampliar la concepción de la estética agustiniana a una escala que incorpora, sin contradicciones intolerables, la herencia helénica del neplatonismo en el

(10) Algunos ejemplos de la manera de juzgar esta cuestión por parte de Svoboda: "los teólogos atribuyen, naturalmente, poca importancia a la estética agustiniana en relación con sus ideas teológicas" (K. Svoboda, L'esthétique, op. cit.p.5). En otro lugar: "Agustín abandona a menudo el tema teológico para enredarse con problemas estéticos" (Ibid., p.102). Para un punto de vista totalmente opuesto Cf. H.U. von Balthasar, Gloria. Una estética teológica, trad. esp. Madrid, 1985; cf. ad. W. Anneliese Meiss (Hna.), Hans Urs von Balthasar y Karl Barth: puntos y contrapuntos de dos modos de pensar, in Teología y Vida, vol. XXXVIII (1997), pp. 301-330. 
tema central de la belleza -vía Plotino- y, al mismo tiempo, la recia exigencia de atención al orden de la belleza creada que trae consigo la experiencia vivida del misterio cristiano, así como su reflexión filosófica y teológica respectivamente.

Lo que nos interesa destacar de la tesis de O'Connell es que lo que busca en Agustín es, ante todo, una estética encarnada y que, naturalmente, esta formulación de la estética agustiniana se halla inicialmente abierta a una consideración totalmente positiva respecto de la totalidad de los aspectos inmediatamente sensibles que integran la experiencia de la belleza y de la imagen correspondiente, y que, por lo mismo, considera de una manera igualmente positiva el papel de las bellas artes en su rica diversidad de contenidos y operaciones artísticas. Esto se hace evidente en el penúltimo capítulo de su libro, intitulado precisamente: La última estética de Agustín (11). Allí O’Connell señala los intereses -positivos- de Agustín por todo lo creado, por el cuerpo del hombre, por el símbolo y el simbolismo como expresión genuina e imprescindible del arte.

Una estética encarnada encontraría su correlato teológico en la doctrina cristiana de la resurrección de los cuerpos, así como en la doctrina de la inmortalidad del alma y la del amor al prójimo en el sentido neotestamentario, que incluye dramáticamente a "los enemigos". Y, sobre todo, en la doctrina de la Creatio ex nihilo, en la del hombre como imago Dei y en la Encarnación del Verbo de Dios. De todos modos, O'Connell no llega a soluciones satisfactorias por el peso inútil de la suposición que ha hecho sobre la preexistencia del alma y por las consecuencias que este hecho desencadena en el orden de una estética que no podemos seguir en detalle aquí. En síntesis, se puede decir que a pesar de su hipótesis brillante: estudiar el lenguaje artístico de Agustín, quien, por otra parte, ha formulado una estética ya en los escritos tempranos, y a pesar de la idea, justa, de buscar en Agustín - pensador cristiano- una estética encarnada, los resultados son precarios. En efecto, O'Connell se ve forzado a admitir la presencia de dicotomías entre el reino de lo visible y el de lo invisible; el de lo temporal y el de lo eterno y, más grave aún: reconocer que el movimiento que va de uno al otro no es natural (12). Ahora bien, si esta es la conclusión de la aproximación de O’Connell, la estética se hace inviable en Agustín.

La aporía mencionada arriba es la que permite apreciar en todo su valor la aproximación de C. Harrison. La estudiosa establece que el pensamiento de Agustín sobre la belleza no puede reducirse a la indagacón -útil- de sus fuentes filosóficas, ni tampoco -cualquiera sea el brillo y el interés de esta hipótesis- al estudio del lenguaje artístico de Agustín, el cual manifiesta una verdadera praxis estética que, sin embargo, contraría de manera grave afirmaciones teóricas de los escritos tempranos de Agustín, todo esto en la misma época inicial. Harrison insiste en la necesidad de considerar otras fuentes -las escriturísticas- y tomarlas absolutamente en serio para el análisis de la estética de Agustín. Es evidente que las Escrituras, tanto en el $A T$ cuanto en el $N T$, proponen un lenguaje religioso que es ininteligible sin sus contenidos poéticos y simbólicos, sin el valor ontológico y espiritual de sus poderosas imágenes. En suma: ese lenguaje y el pensamiento religioso que contiene es, inmediatamente, estético. Su influencia en la elaboración de una teoría estética es

(11) Cf. R..J. O'Connell, Art and the Christian Intelligence in Saint Augustine, ed. cit.

(12) Cf. R.J. O'Connell, Art and the Christian Intelligence..., ed. cit. p.146. Cf. ad. la crítica pertinente que hace C. Harrison, Beauty and Revelation, ed. cit. pp. 34-36. 
decisiva y hace posible, justamente, el carácter encarnado de la estética que busca en vano O'Connell.

C. Harrison propone, acertadamente, examinar -una vez más- la idea platónica y neoplatónica de Forma y formas, las cuales explican el recurso filosófico-teológico en la estética de Agustín al concepto de Arquetipo que está necesariamente por encima del alma y de su interioridad más profunda y cierta; y, por otra parte, señala la insistencia de Agustín en las leyes y normas para juzgar en materia de verdad y belleza. Y, lo más importante para nuestro tema de la imagen como icono, el examen de las ideas de Forma y de formas ilumina la densidad diversa de dos ámbitos de la realidad: la de los arquetipos ideales y la de sus imágenes en la experiencia de los sentidos. Toda la cuestión consiste, tanto en Platón cuanto en Agustín, en que el hombre sea capaz de mirar y ver a través de las imágenes corpóreas la verdad de la belleza.

La imagen como ícono se inserta en la presencia de la Forma Ideal de la Belleza en el reino temporal de las cosas sensibles y visibles y, entonces, en su continuidad. Como explica bellamente E. Krakowski en su comentario a Plotino: "la belleza aquí ya no es un simple tipo, un modelo inmóvil que los objetos de los sentidos imitan o representan como meros reflejos; la Idea ya no está más separada de la realidad, la cual pertenece a su forma de vida, ya que la esencia realizada en la forma de la cual ella está penetrada es su actividad creativa. Lejos de ser una simple copia de la Idea, una cosa actual bella en su realización, la Idea toma cuerpo y se encarna" (13). Este texto -precioso- que ilumina la cuestión de la belleza para el gran neoplatónico, se aplica a la realidad mediadora de la imagen como ícono, en el pensamiento de Agustín. En efecto, la Belleza para Agustín traduce su realidad en la lengua latina y el pensamiento correspondiente en los términos forma/formosus y, en cada caso, es inseparable de una existencia dada por Dios y orientada hacia Él. Ahora bien, la Belleza tiene una realidad y una importancia enorme para la meditación incesante del doctor de Hipona: en la Creación ha habido, ciertamente, un formar todas y cada una de las cosas, incluido el hombre (imagen y semejanza de Dios); en la Historia ha habido y hay continuamente un formar $\mathrm{y}$, por lo mismo, un ordenar en términos de Providencia el significado total de la Historia concentrada en un acontecimiento único cual es la Encarnación del Verbo de Dios. La Encarnación manifiesta la Forma Eterna Divina y, por otra parte y al mismo tiempo, manifiesta un formarse de la humanidad necesariamente corpórea del Verbo Divino. Todo este inmenso conjunto asume un aspecto de inocultable belleza presente en la experiencia inmediata del hombre y de las cosas, esto es: en la realidad Creada que se comporta como un espejo relativamente velado por la temporalidad y la corporalidad.

\section{ALGUNAS CONCLUSIONES}

Deseo e ícono pueden ser considerados a favor de ciertas categorías que los iluminan respectivamente (14). Así, el deseo es siempre relación con un objeto

(13) Cf. E. Krakowski, L'esthétique de Plotin et son influence, Paris, 1929, p.159. Las cursivas son nuestras.

(14) Cf. I. Bochet, op. cit., pp. 222-231. 
determinado. Pero Dios excede absolutamente la dimensión en la cual el hombre habla de objetos, es transobjetivo: más aún es Uno-Trino-Personal. Por esto, precisamente, Dios establece una relación personal con el hombre en la que se destaca el llamado o vocación por parte de Dios y la respuesta libre por parte del hombre. El deseo de Dios afirma al hombre en su ser-en-relación no solo dialógica sino, ante todo, vocacional y por lo mismo ontológica. La conversio a Dios marca el comienzo de una reorientación que se espera sea constante en el deseo y la relación a su fin último y propio. El deseo, en segundo lugar, comporta un dinamismo que impulsa al hombre hacia un bien-fin absolutamente trascendente. Finalmente, este hecho mismo comporta una dilatación del alma, una real y verdadera extensión de su capacidad (Tr. In Eo. Ioh. IV, 6).

El inacabamiento del hombre, su ser in via, halla realización plena -formasolo en Dios y esto significa, también, el sosiego profundo y último a la inquietud fundamental del hombre en el acogimiento de Jesucristo (Confes. I, 1, 1). En este sentido, la extentio iconica hace que la experiencia del hombre sea progresivamente cristiforme.

El deseo de Dios asemeja -via extentio- el hombre a Dios; el hombre creado a imagen y semejanza de Dios lleva en sí mismo la forma de su deseo fundamental. La historia de todo hombre consiste, entonces, en hacerse, paso a paso, semejante a Aquel a Quien desea. Crecer desde la forma de la imagen hacia la forma del Modelo, desde el ícono viviente hacia la realidad absoluta y no menos viviente de Dios en un proceso de identificación abierta e incompleta. El deseo de Dios y el hombre en cuanto ícono viviente de Dios manifiestan el ser del hombre como ser-para-Dios. 